EGU21-12122, updated on 19 Aug 2021

https://doi.org/10.5194/egusphere-egu21-12122

EGU General Assembly 2021

(c) Author(s) 2021. This work is distributed under

the Creative Commons Attribution 4.0 License.

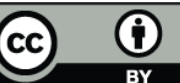

\title{
Mafic magma as metal source for Sb-W-Hg mineralisation? A case study of the early Carboniferous mafic magmatic event from the French Armorican Variscan belt
}

\author{
Anthony Pochon, Giada lacono-Marziano, Saskia Erdmann, Eric Gloaguen, and Johann Tuduri \\ Université d'Orléans/CNRS/BRGM/ISTO, UMR 7327, F-45071 Orléans, France (pochon.anthony@gmail.com)
}

A possible genetic link between Sb-W-Hg mineralisation (vein-type and stratabound) and mafic magmatism has been proposed for the Variscan belt during the early Carboniferous, but this hypothesis remains to be rigorously assessed. The metal enrichment of the fluids producing Variscan Sb-W-Hg deposits may be ascribed to (i) crystallization of metal-rich primary mafic magma, and/or (ii) exsolution of metal-rich magmatic fluids and their local concentration, and/or (iii) an efficient hydrothermal leaching of surroundings sedimentary rocks by fluid release due to contact metamorphism. The aim of this project is thus to estimate the contribution of mafic magmas as the metal source of Sb-W-Hg deposits. Our case study focuses on the Saint-Jean-duDoigt gabbro from the Variscan Armorican belt, Brittany, France. We have characterized the Sb-, $\mathrm{W}$-, and $\mathrm{Hg}$-carrier minerals (e.g. Fe-Ti oxides) and volatile-bearing minerals (e.g. apatite) to quantify the metal content and volatile inventory during purely magmatic and magmatichydrothermal processes. Abundant primary amphibole and biotite, and the presence of pegmatoids indicate that the melt was likely to be enriched in volatile. An alteration gradient is observed from the base of the intrusion towards its roof. Moreover, high temperature replacement mineral reactions (e.g. saussuritization) mainly occur in the upper part of the intrusion, suggesting that magmatic fluids were accumulated toward the top of the intrusion. Cathodoluminescence and apatite compositions are taken to record the magmatic-hydrothermal transition and hydrothermal alteration. Apatite ranges in composition between fluorapatite and fluor-hydroxyapatite, but the latter is largely more frequent. A high volatile content of the silicate melt is suggested by the high proportion of negative-shaped fluid inclusions into ilmenite (up to 15 $\%$ crystal volume), which hint at a primary magmatic origin. SEM, EPMA and LA-ICP-MS investigations show that magmatic fluid inclusions contain significant amounts of $\mathrm{Sb}$ and $\mathrm{W}$. Our results highlight that metals (i.e. Sb, W) were partly partitioned into the fluid phase during magma crystallization and degassing. In addition, trace element content of ilmenite also records metal enrichment from the base to the intrusion roof, probably due to magma degassing and deuteric/metasomatic processes. We therefore propose that mafic magmatism is a potential metal source of the early Carboniferous $\mathrm{Sb}-\mathrm{W}-\mathrm{Hg}$ mineralization event and should be considered as possible sources for other Sb-W-Hg province worldwide. This work was funded by the ANR (ANR-19-MIN2-0002) and author's institutions in the framework of the ERA-MIN2 AUREOLE project (https://aureole.brgm.fr). 
